\title{
Assessment of economic damage thresholds of some pests infesting tomato crop and its impact on losses in Egypt
}

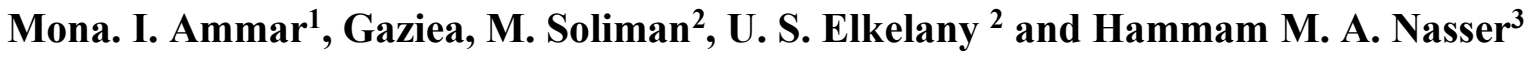 \\ ${ }^{1}$ Plant Protection Research Institute (PPRI), Agriculture Research Center (ARC), Dokki 12618, Giza, \\ Egypt. \\ ${ }^{2}$ Plant Pathology Department, Nematology Lab. National Research Centre, Dokki Giza, Egypt. \\ ${ }^{3}$ Agriculture Economics Research Institute, Agriculture Research Center (ARC), Giza, Egypt.
}

Received: 25 Sept. 2019 / Accepted 14 Nov. 2019 / Publication date: 25 Nov. 2019

\begin{abstract}
The experiment was carried out for two successive seasons (2017 and 2018) at EL- Giza Governorate. In both seasons tomato plant of variety "Elisa" were cultivated to obtain different levels of infestation by Tomato leafminer (TLM) Tuta absoluta and the root- knot nematodes Meloidogyne incognita of tomato plants were sprayed periodically with (Abamectin benzoate). Results showed that the obtained correlation " $r$ " values indicating a strong negative relationship between the density of infestation (T. absoluta and M. incognita) and the corresponding crop yield of tomato produced. Economic threshold levels and economic injury level of T. absoluta and M. incognita to be used as a tool for controlling under field conditions were determined. Data indicated that economic threshold Level (E.T.L)] for (TLM) was 40 to 49 larvae / 20 leaves, and the economic injury level (E.I.L)] was 49 to 84 larvae / 20 leaves whereas at this level of infestation control measures must be applied. $M$. incognita soil naturally infected with nematodes, data indicated that (E.T.L) was 95 to $114 \mathrm{~J} 2 / 200 \mathrm{~g}$ soil. The (E.I.L) was 114 to $170 \mathrm{~J} 2 / 200 \mathrm{~g}$ soil whereas at this level of infestation control measures must be applied. Mean number of galls of $M$. incognita data indicated that (E.T.L) was 119 to 183 galls/ plant and ( E.I.L) was 183 to 293 galls/plant whereas at this level of infestation control measures must be applied. For egg-masses of M. incognita, data indicated that (E.T.L) was 101 to 162 egg-mass/plants and (E.I.L) was 162 to 260 egg-mass/plants whereas at this level of infestation control measures must be applied. the results of the economic evaluation should be recommended to rely on the fourth treatment current experiments that advice for spraying the bio-pesticide to control pests four times according to the technical recommendation that had positive impact on the net return and profits.
\end{abstract}

Keywords: Economic Threshold Level, Damage thresholds, Economic Injury Level, Tuta absoluta, Meloidogyne incognita, Tomato, Abamectin benzoate, Yield, Treatment, Bio-pesticide, control, pests and Economic Evaluation

\section{Introduction}

Tomato (Lycopersicum escutentum, Mill.) is an important vegetable crop which has large popularity and demand in Egypt. It's an important source of vitamins and nutrients, and an economically important agricultural commodity. Moreover, it is an important cash crop for small holders and medium scale commercial farmers. Egypt is considered second of the important tomato producers in the world (WPTC, 2019). The summer tomato crop (Elisa variety) is one of the main vegetable crops, whether for fresh consumption or for processing, which affects both farmers and consumers, It also make a profit and economic return on farmers that increases their income, The area of tomatoes represents about $21.3 \%$ of the area of summer vegetables estimated at 928.1 thousand faddan during 2017, Its cultivation is concentrated in Nubariya, Alexandria, Matrouh, Beheira and Sharkia Governorates, in addition to El- Giza and Minya Governorates. The area of their tomatoes represents about $83.4 \%$ of the total area of tomatoes amounting to about 197.6 thousand faddan in 2017, the governorate of Giza, where the experiment is ranked seventh as the most important provinces producing summer tomatoes with an area of about 8.77 thousand faddan representing $4.4 \%$ of the total area of summer tomatoes. The production of tomatoes is constrained by several destructive pests and diseases that cause severe damages (Khalil 2013). Since the tomato is infected 
by many pests, including sap-sucking pests and Tomato leafminer (TLM), Tuta absoluta (Alston 2007; EPPO 2008\&2009; Desneux et al. 2010; FERA 2009 and Sabbour 2014). Tuta absoluta (Meyrick 1917) is leaf-mining moth of the family Gelechiidae (Lepidoptera) and consider as one of the most serious pests of tomato decreasing the fruit quality in both field and greenhouse tomato plants (Gilardo'n et al., 2001; Tropea Garzia et al., 2012). The root-knot nematode, Meloidogyne spp has been found to cause major damages in quality and quantity of yields in varied crops; as are being responsible for at least 90\% of all damage caused by nematodes (Eloh et al. 2016; Khan et al. 2010 and Osman et al. 2012) Meloidogyne spp. annual losses was up to $29 \%$ in tomato (El-Nagdi, et al. 2019; Sikora and Fernandez 2005). At the past decade in Egypt, the main control technique involved the use of chemical insecticides and nematicides; however, the negative consequences of these products to the environment and their inefficiency after long-term use have resulted in the prohibition or restrictions of most of the chemicals used. Therefore, there is an increasing requirement for developing non-chemical alternative methods for the management of TLM and the root-knot nematode (El-Nagdi et al. 2019; Tropea Garzia et al., 2012). Recently, Bio-control methods have received increasing interest because of their high effectiveness and environmentally friendly characteristics (Varkeya et al., 2018). Abamectin is one of the suggested alternative bio-rational tools that belong to avermectin group, macro cyclic lactones metabolites produced by a natural fermentation of the bacterium Streptomyces avermitilis (Omura and Shiomi 2007, Pitterna, et al., 2009). As a bio-pesticide, Abamectin benzoate has effectively prevented lepidopteran pests; moreover, it had an antagonistic effect on nematodes. Khalil, 2013; Arora et al., 2000; El-Nagdi 2001; El-Nagdi and Youssef, 2004 and Korayem et al., 2008). Damage caused by nematodes to plants is directly proportional to their population densities in soil, and their reproduction potentials on the plant (Barker and Olthof, 1976 and Korayem et al., 2015). The minimal density that causes a measurable reduction on plant growth or yield is regarded as the damage threshold density (Barker and Nusbaum, 1971; ), and when the cost of production and the value of a given crop are considered, the term economic threshold density (Minimal nematode density that causes economic loss) is used. The threshold density varies with nematode species, race, plant variety and environment (Barker and Olthof, 1976; Korayem, et al., 2012 \& 2015). The use of nematode threshold levels in nematode management programs avoided crude use of nematicides that pollute the environment. The nematode threshold levels, damage threshold (the nematode density at which the yield begin to decrease) and economic threshold (the nematode density at which cost of the yield loss equals the cost of nematode control) have important roles in the decision-making process and development of management strategies. In Egypt, the estimation of nematode threshold levels, damage threshold level or tolerance limit as well as the expected yield loss of due to different population of nematodes are very limited.

The aims of this study were to assessment the economic damage thresholds of some pests (Tomato leafminer (TLM), Tuta absoluta and the root- knot nematodes Meloidogyne incognita infesting tomato crop and its impact on losses in Egypt.

\section{Material and Method}

\section{Location and design of the experiment:}

This experiment was carried out for two successive seasons (2017 and 2018) at Kafre - Hakim village, El-Giza, Governorate, Egypt. The soil in the fields was heavily infested with root knot nematodes, M. incognita initial population (Pi) about 132/200g soil. Average of annual temperatures was in the range of $25-30^{\circ}$, makes the location favorable for growth of tomato. Tomato seedling C.V "Elisa" was sown in 1st of March and left until 1st of July in an area was about $\left(525 \mathrm{~m}^{2}\right)$. Then area was divided into ten equal rectangular blocks separated from each other by belts of 2 meters wide. Each (treatment) block $\left(52.5 \mathrm{~m}^{2}\right)$ that subdivided into 3 replicates. The plots were then split into two equal divisions; one used for sampling and the other left untouched until harvesting as a control treatment (for the yield estimation). To obtain different levels of infestation by T. absoluta and $M$. incognita of tomato plants were sprayed periodically with (Abamectin benzoate) $60 \mathrm{gm} / 200 \mathrm{~L}$. The bio-pesticides treatment was applied by means of a compression knapsack sprayer. In both seasons, spraying started on March 22nd All the experimental plots received the same regular agricultural practices. 
Table 1: Shows the Treatment dates by (Abamectin benzoate) $60 \mathrm{gm} / 200 \mathrm{~L}$ throughout two successive seasons, 2017- 2018 at El-Giza Governorate.

\begin{tabular}{|c|c|c|c|c|c|c|c|c|c|c|}
\hline $\begin{array}{l}\text { Treatments } \\
\text { (No.of spraying) }\end{array}$ & 1 & 2 & 3 & 4 & 5 & 6 & 7 & 8 & 9 & 0 \\
\hline 1 & $22 / 3$ & $22 / 3$ & $22 / 3$ & $22 / 3$ & $22 / 3$ & $22 / 3$ & $22 / 3$ & $22 / 3$ & $22 / 3$ & \\
\hline 2 & & $11 / 5$ & $25 / 4$ & $16 / 4$ & $11 / / 4$ & $8 / 4$ & $6 / 4$ & $4 / 4$ & $2 / 4$ & \\
\hline 3 & & & $29 / 5$ & $11 / 5$ & $1 / 5$ & $25 / 4$ & $21 / 4$ & $17 / 4$ & $13 / 4$ & $=$ \\
\hline 4 & & & & $5 / 6$ & $21 / 5$ & $12 / 5$ & $6 / 5$ & $30 / 4$ & $24 / 4$ & : \\
\hline 5 & & & & & $10 / 6$ & $29 / 5$ & $21 / 5$ & $13 / 5$ & $5 / 5$ & కิ \\
\hline 6 & & & & & & $15 / 6$ & $3 / 6$ & $26 / 5$ & $16 / 5$ & \\
\hline 7 & & & & & & & $18 / 6$ & $8 / 6$ & $27 / 5$ & \\
\hline 8 & & & & & & & & 216 & $7 / 6$ & \\
\hline 9 & & & & & & & & & $18 / 6$ & \\
\hline 10 & & Control & & & & & & & & \\
\hline
\end{tabular}

\section{Estimation of Tuta absoluta (Meyrick) infestation:}

Starting on March 15th until end of July and continued till harvest, weekly samples of 20 leaves were collected at random from each replicate. The samples were kept in paper bags and transferred to the laboratory to examine and count the population density of T. absoluta.

\section{Estimation of infestation Meloidogyne incognita:}

Starting on March 15th until end of July and continued till harvest, 3 week samples of 15 soil sample were collected at random from each replicate. The samples were kept in plastic bags and transferred to the laboratory to examine and count existed nematodes. Estimation of nematodes juveniles (J2s) in the soil was made by collecting a composed sample from each replicate micro plot directly before transplanting. First day prior to transplanting into the field Abamectin benzoate was applied to the seedling of the tomato plants for drenching the soil as protected tools. Plants were observed regularly for any disease symptoms. Monthly 3 samples of soil from rhizosphere of plant were collected at random from each replicate. At the end of experiment, ten plants from each plot were chosen at random and uprooted. Soil population of $M$. incognita juveniles, number of galls and egg-masses were counted. It was obtained from tomato roots collected from a field. M. incognita $\mathrm{J} 2 \mathrm{~s}$ were extracted from $200 \mathrm{~g}$ soil by sieving decanting techniques and counted under a light microscope. Tomatoes were harvested; on July 1st at the two investigated seasons 2017 - 2018. The weight produced by 65 tomato plants in each replicate was recorded, and the average weight of yield for each treatment was calculated.

\section{Statistical Analysis:}

Statistical analysis was done using analysis of variance (Anova) by SAS program 1999. Significant differences were determined at level of $p=0.05$. Yield of tomato were plotted against population densities of (TLM and M. incognita) to depict the regression lines for estimating damage threshold levels.

\section{Research Methods and Data Sources:}

The study was based on the method of descriptive and quantitative analysis where averages were calculated for the important economic and technical variables related to the subject. In addition to use of the most important indicators and criteria of productivity and economic efficiency to identify the productive and economic efficiency of different treatments on the tomato yield, include the criteria for the return on the invested pound, CBR (cost benefit ratio), in addition to estimating the losses resulting from the use of the bio-pesticide and economic impact.

The investigation depended on two resources of data: firstly that published by the Ministry of Agriculture and Land Reclamation, the second resource of data on which, the study relied mainly is the primary data, that was collected by conducting a field experiment on an area of $525 \mathrm{~m} 2$ divided into 10 blocks each block area of $52.5 \mathrm{~m} 2$ to measure the impact of difference application of the biopesticide (Abamectin benzoate) on the yield during two seasons 2017 and 2018. 


\section{Results and Discussion}

\section{The infestation-yield relationship:}

Negative and highly significant relationship between different levels of population density of (T. absoluta) and tomato's yield of shown in Fig. 1 Negative and highly significant relationship between different levels of population density of (T. absoluta) and tomato's yield of shown in Fig. 1 whereas correlation coefficient " $r$ " was -0.958 and regression " $b$ " was were $-5.14 \mathrm{Kg}$ and Coefficient of determination was 0.932 for two successive seasons $2017 \& 2018$.

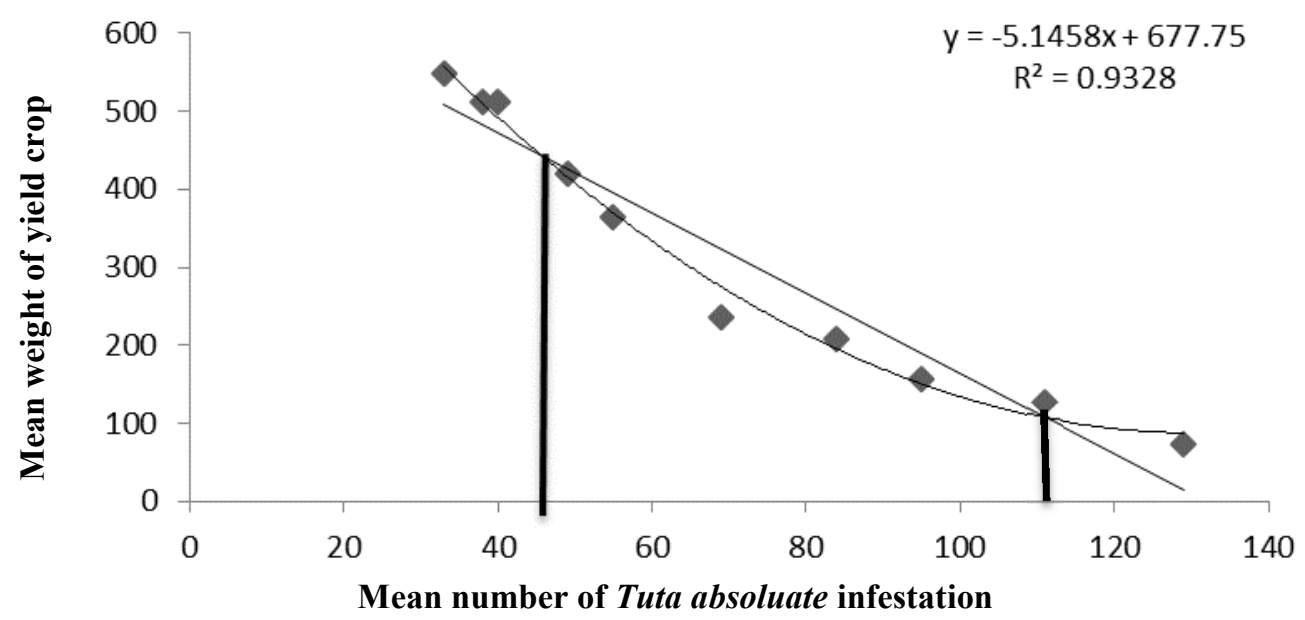

Fig. 1: Relationship between the population density of (Tuta absoluate) and tomato' yield under field conditions during 2017 and 2018.

Population density (Pi) of $M$. incognita $\left(\mathrm{J}_{2} \mathrm{~S}\right)$ for all micro plate. Where the average of $M$. incognita initial population (Pi) about $132 / 200 \mathrm{~g}$ soil. For overcoming this problem of convergence of numbers of initial population density were sprayed all microplates periodically with (Abamectin benzoate) as appeared in Table (1), to obtain different levels of nematode density in soil.

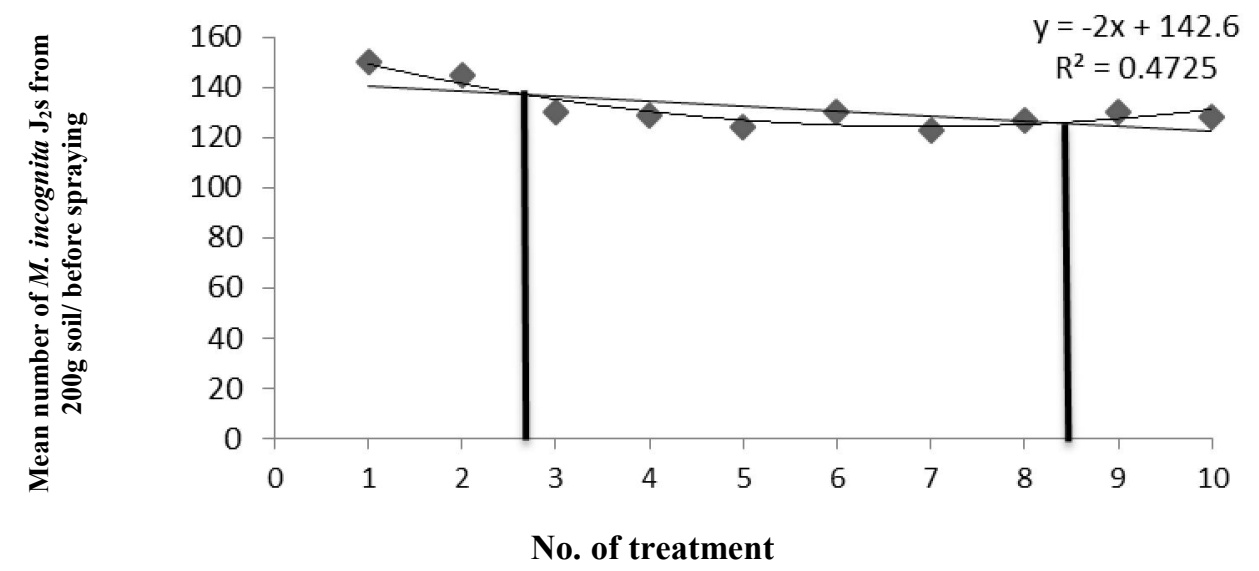

Fig. 2: Relationship between the $M$. incognita $\mathrm{J}_{2 \mathrm{~S}}$ initial population (Pi) before spraying under field conditions during 2017 and 2018.

Figs. (3, 4 and 5) showed negative and highly significant relationship between different levels of initial population density ( $\mathrm{Pi})$ of $\mathrm{M}$. incognita $(\mathrm{J} 2 \mathrm{~s})$, number of galls and number of egg-masses) and of tomato's yield whereas " $r$ " values were $-0.958,-0.848$ and -0.809 , respectively. While " $b$ " values were $-2.34 \mathrm{Kg},-0.97 \mathrm{Kg}$ and $-1.27 \mathrm{Kg}$, respectively. Coefficient of determination were $0.921,0.654$ and 0.723 , respectively for two successive seasons $2017 \& 2018$. 


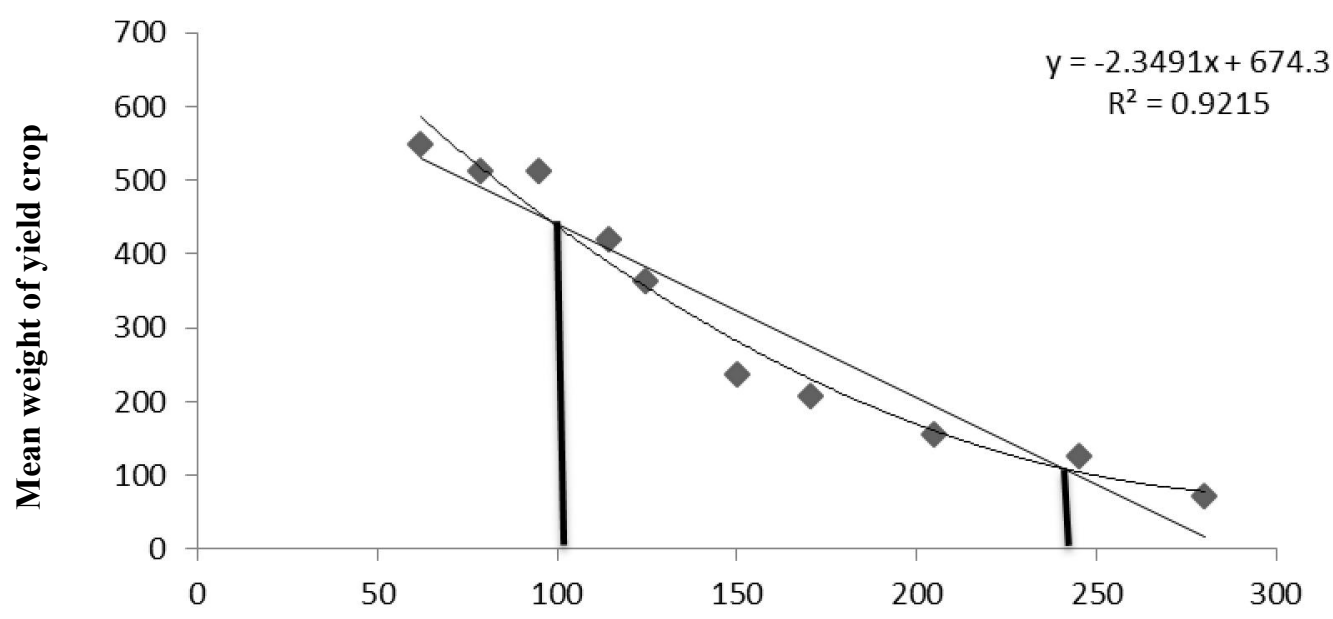

Reference Mean number of $M$. incognita $\mathrm{J}_{2}$ s from $200 \mathrm{~g}$ soil

Fig. 3: Relationship between the M. incognita J2s initial population (Pi) and tomato' yield under field conditions during 2017 and 2018.

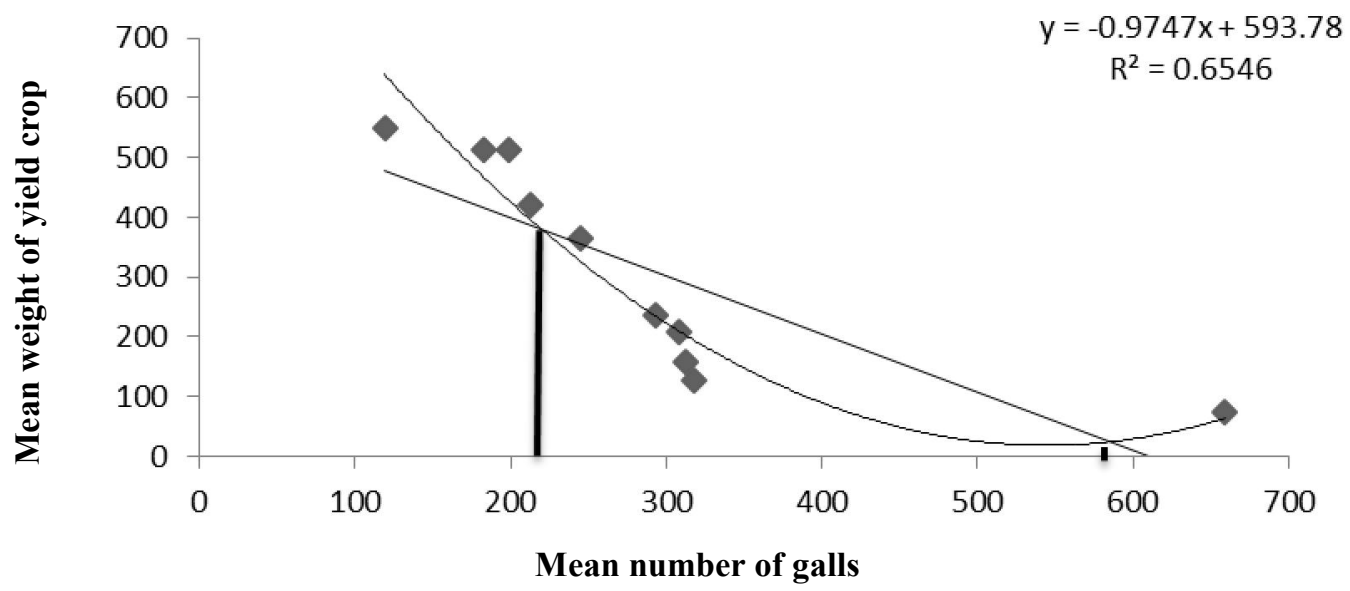

Fig. 4: Relationship between the mean number of $M$. incognita galls and tomato yield under field conditions during 2017 and 2018 .

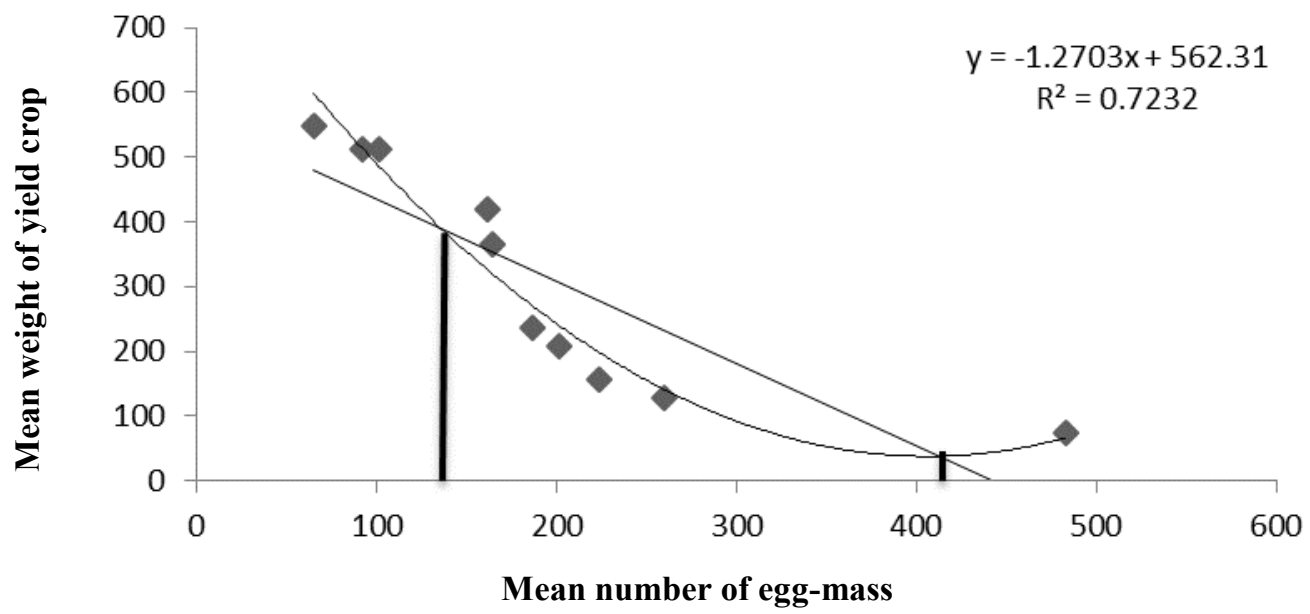

Fig. 5: Relationship between the mean number of $M$. incognita egg-mass and tomato yield under field conditions during 2017 and 2018. 


\section{The approximate damage threshold:}

The injury caused by $T$. absoluta and $M$. incognita in tomatoes during its seasonal activity showed that, this damage occurred during of vegetative growth and formation of tomato fruits. Statistical analysis showed that population density of these $T$. absoluta and $M$. incognita was incognita were highly significant correlated with main yield. This injure are mainly caused decreasing to the amount of tomato's yield harvested. Therefore, losses assessment must be depend on yield weight decline. Estimation of "Economic Levels of Infestation" will be based on correlation different levels of population density of T. absoluta and M. incognita and tomato weight yield per plant. Pedigo et al. (1986) was more convenience to illustrate definition of "Economic Levels".

\section{Tuta absoluta}

Data in the table (2) indicated that population density during the main period of seasonal activity estimation of economic levels of infestation showed that when the population density of $T$. absoluta less than 40 larvae / 20 leaves could be regarded as [General Equilibrium Position (G.E.P)] when population reached to 49 larvae / 20 leaves, the chi-square $\left(\chi^{2}\right)$ value for the yield weight was (8.9) (table chi-square $\left(\chi^{2}\right)$ (7.81 in 0.05)) and significant drop in the weight yield was happened. Therefore, 49 larvae / 20 leaves could be regarded as [Economic Threshold Level (E.T.L)], no need for control measures, but must be ready if population density increases above that level. Afterwards, population density increased upwards from 49 to 84 larvae / 20 leaves, the yield loss decreased for 420.2 to $209 \mathrm{~kg}$, was , significant $\chi^{2}$ value (11.51)significant $\chi^{2}$ value (11.51) (table chi-square $\left(\chi^{2}\right)$ (11.07 in 0.05))was obtained. This level of infestation could be regarded as [Economic Injury Level (E.I.L)], at this level of infestation control measures must be applied. Then, population density increased upwards from 84 to 129 individuals/ samples tomato's yield decreased to $73.1 \mathrm{~kg} /$ the obtain $\chi^{2}$ value (7.9) (table chi-square $\left(\chi^{2}\right)(7.81$ in 0.05$)$ ) was significant. This level of infestation could be regarded as [Economic Damage Level (E.D.L)].

Table 2: Economic injury levels and economic damage threshold in tomatoes infested by Tuta absoluta in El-Giza Governorate during 2017 and 2018 seasons.

\begin{tabular}{ccccccccccccc}
\hline $\begin{array}{c}\text { Mean } \\
\text { number of } \\
\text { larvae }\end{array}$ & 33 & 38 & $\begin{array}{c}40 \\
\text { (G.E.P.) }\end{array}$ & $\begin{array}{c}49 \\
\text { (E.T.L })\end{array}$ & 55 & 69 & $\begin{array}{c}84 \\
(\text { E.I.L) }\end{array}$ & 95 & 111 & $\begin{array}{c}129 \\
\text { (E.D.L) }\end{array}$ \\
\hline $\begin{array}{c}\text { Weight of } \\
\text { yield }\end{array}$ & 598 & 512.9 & 513 & 420.2 & 364 & 236.2 & 209 & 156.7 & 127 & 73.1 \\
\hline
\end{tabular}

G.E.P= General Equilibrium Position, E.T.L =Economic Threshold Level, E.I.L= Economic Injury Level, E.D.L= Economic Damage Level.

\section{Meloidogyne incognita}

Data in table (3) indicated that the initial population density (Pi) of $M$. incognita was less than 95 juveniles $\mathrm{J}_{2} / 200 \mathrm{~g}$ soil that could be regarded as (G.E.P). When population reached to $114 \mathrm{~J}_{2} / 200 \mathrm{~g}$ soil, the chi-square $\left(\chi^{2}\right)$ value for the yield was (13.5) (table chi-square $\left(\chi^{2}\right)(7.81$ in 0.05$)$ ), and highly significant drop in the yield was occurred. Therefore, $114 \mathrm{~J}_{2} / 200 \mathrm{~g}$ soil could be regarded as (E.T.L) therefore no need for control measures, but must be ready if population density increases above that level. Afterwards, population density increased upwards from 114 to $171 \mathrm{~J}_{2} / 200 \mathrm{~g}$ soil, the yield loss decreased to 420 to $209 \mathrm{~kg}$, the obtain $\chi^{2}$ value (9.1) (table chi-square $\left(\chi^{2}\right)(7.81$ in 0.05$)$ ) was significant. This level of infestation could be regarded as (E.I.L), At this level of infestation control measures must be applied. Then, population density increased upwards from 170 to 245 individuals/sample tomato's yield decreased to $127 \mathrm{~kg}$. obtained $\chi^{2}$ value (8) (table chi-square $\left(\chi^{2}\right)$ (5.99 in 0.05)) tomato's was significant. This level of infestation could be regarded as (E.D.L)].

\section{Mean number of galls of $M$. incognita galls.}

Data in table (3) indicated that the mean number of galls of $M$. incognita less than 119 galls/plant could be regarded as (G.E.P). When population reached to 183 galls/ plant, the chi-square $\left(\chi^{2}\right)$ value for the yield was (8.6) (table chi-square $\left(\chi^{2}\right)(7.81$ in 0.05$)$ ), significant drop in the yield was occurred. Therefore, 183galls/plant could be regarded as (E.T.L), whereas no need for control measures, but must be ready if mean number of galls increases above that level. Afterwards, 
population density increased upwards from 183 to 293 galls/plant, the yield decreased to 512.85 to $236.27 \mathrm{~kg}$ obtained $\chi^{2}$ value (19.5) (table chi-square $\left(\chi^{2}\right)(9.49$ in 0.05$)$ ) was highly significant. This level of infestation could be regarded as (E.I.L); at this level of infestation control measures must be applied. Then, mean number of galls increased upwards from 293 to 659 galls/ sample the yield decreased to 236.27 to $73.12 \mathrm{~kg}$ and the obtained $\chi^{2}$ value (143) (table chi-square $\left(\chi^{2}\right)(9.49$ in 0.05$)$ ) was highly significant. This level of infestation could be regarded as (E.D.L)].

\section{Egg masses of M. incognita}

The data in table (3) indicated that the egg masses of $M$. incognita less than 101 egg- mass/ plant could be regarded as (G.E.P). When population reached to 162 egg-mass/ plant, the chi-square $\left(\chi^{2}\right)$ value for the yield was (34.7), (table chi-square $\left(\chi^{2}\right)(7.81$ in 0.05$)$ highly significant drop in the yield was occurred. Therefore, 162 egg-mass/ plant could be regarded as (E.T.L), no need for control measures, but must be ready if egg-mass increases above that level. Afterwards, population density increased upwards from 162 to 260 egg mass/plant, he yield decreased to 420 to $127.4 \mathrm{~kg}$, to obtain significant $\chi^{2}$ value (21.9) (table chi-square $\left(\chi^{2}\right)$ (11.07 in 0.05). This level of infestation could be regarded as (E.I.L); at this level of infestation control measures must be applied. Then, egg-masses increased upwards from 260 to 483 individuals/ sample the yield decreased 127.4 to $73.12 \mathrm{~kg}$ obtaining highly signification $\chi^{2}$ value (36.67) (table chi-square $\left(\chi^{2}\right)(3.84$ in 0.05$)$. This level of infestation could be regarded as (E.D.L)].

Table 3: Economic injury levels and economic damage threshold in tomatoes infested by number of M. incognita $\mathrm{J}_{2}$ in soil, number of and number of egg mass) in El-Giza Governorate during 2017 and 2018 seasons.

\begin{tabular}{cccc}
\hline $\begin{array}{c}\text { Mean number of }\left(\mathrm{J}_{2}\right) / 200 \\
\text { g soil }\end{array}$ & Mean number of Galls & $\begin{array}{c}\text { Mean number of Egg- } \\
\text { mass }\end{array}$ & Weight of yield \\
\hline 62 & (G.E.P) 119 & 65 & 598.00 \\
79 & (E.T.L $) 183$ & 92 & 512.85 \\
(G.E.P) 95 & 199 & (G.E.P) 101 & 512.69 \\
(E.T.L) 114 & 213 & (E.T.L ) 162 & 420.23 \\
124 & 245 & 164 & 364.00 \\
150 & (E.I.L) 293 & 187 & 236.28 \\
(E.I.L) 170 & 308 & 201 & 208.73 \\
205 & 313 & 224 & 156.65 \\
(E.D.L) 245 & 318 & (E.I.L) 260 & 127.40 \\
280 & (E.D.L) 659 & (E.D.L) 483 & 73.125 \\
\hline
\end{tabular}

G.E.P= General Equilibrium Position, E.T.L =Economic Threshold Level, E.I.L= Economic Injury Level, E.D.L= Economic Damage Level

\section{Interaction between the T. absoluta and M. incognita in tomatoes yield crop}

Data in table (4) indicate that the interaction between the injury caused by T. absoluta and $M$. incognita in tomatoes yield were highly significant interaction. T. absoluta $*$ M. incognita $\left(\mathrm{j}_{2} \mathrm{~S}\right)$ whereas $\mathrm{F}$ value $=112.343 * * *$ and explained variance $(\mathrm{E} . \mathrm{V})=.80 \%$.

Table 4: Interaction between the T. absoluta and M. incognita $\left(\mathrm{J}_{2} \mathrm{~s}\right)$ in tomatoes yield crop in El-Giza Governorate during 2017 and 2018 seasons.

\begin{tabular}{lccccc}
\hline Source & Type III Sum of Squares & df & Mean Square & F & Sig. \\
\hline Corrected Model & 738943.2 & 1 & 738943 & 112.343 & $2.6 \mathrm{E}-11$ \\
Intercept & 3218189 & 1 & 3218189 & 489.267 & $2.8 \mathrm{E}-19$ \\
T. absoluta $*$ M. incognita $(\mathbf{j} 2 \mathbf{2})$ & 738943.2 & 1 & 738943 & 112.343 & $2.6 \mathrm{E}-11$ \\
Error & 184172 & 28 & 6577.57 & & \\
Total & 4006646 & 30 & & & \\
Corrected Total & 923115 & 29 & & \\
\multicolumn{4}{c}{ R Squared $=.800$ (Adjusted R Squared $=.793)$} & \\
\hline
\end{tabular}




\section{Effect of one unit of pests on the productivity of yield}

Results Effect of one unit of pests on the productivity of crop yield. Results showed that one larvae of T. absoluate caused reduction percentages of about $1.66 \%$ as an average in tomato's yield during $2017 \& 2018$.

Results showed that one juveniles of $M$. incognita caused reduction percentages of about $0.74 \%$ as an average in tomato's yield's during 2017\&2018, respectively.

\section{Economic assessment of damage and control cost}

\section{This part aims to evaluate net profits when Appling control measures.}

Data in table (5) indicate that the average yield of tomatoes in current experiment was about $316 \mathrm{~kg} /$ block, ranging from a minimum of about $73.1 \mathrm{~kg} /$ block for treatment $10^{\text {th }}$ (control) and a maximum of about $548 \mathrm{~kg} /$ block for the fourth treatment. Experimentally, total costs of the experiment averaged about 518.5 LE / block, where the lowest cost was for tenth treatment (control) while the highest cost was about $775 \mathrm{LE} /$ block for the $9^{\text {th }}$ treatment, As for the total revenue for the experiment, it is clear that data the averaged about $568.8 \mathrm{LE} / \mathrm{block}$, with a minimum amount of LE $131.6 / \mathrm{block}$ for the $10^{\text {th }}$ treatment and a maximum of $986.4 \mathrm{LE} /$ block for treatment no. 4 , The net return on the average value of the experiment was about $50.3 \mathrm{LE} / \mathrm{block}$, where treatment 9 achieved the maximum loss estimated at $399.3 \mathrm{LE} /$ block while the transaction 4 achieved the highest net return estimated at $496.4 \mathrm{LE} / \mathrm{block}$, This difference in productivity, costs, revenues and net yield is due to the positive effect of the use of the bio-pesticide on productivity in treatment No. 4 of the experiment and thus the positive impact on revenue and net return where the best transactions in terms of those indicators compared to the rest of the treatments in the experiment, While the treatment number 9 despite the high productivity compared to the treatment number 10 (control), it achieved the maximum loss in net return, which is due to the high cost of the bio-pesticide used as a result of wasteful use of that treatment.

As for the economic evaluation indicators, the data indicates that the return on the investor of one L.E. achieved the lowest value of the transaction number $7^{\text {th }}$ in the experiment, where it amounted to about 0.14 , which means that every pound investor makes a net profit estimated at about 0.14 pounds, while its highest value is about 1.01 , that is, each invested pounds will make a profit estimated at 1.01 pounds, The benefit -cost ratio (CBR) of that crop shows the 4 th treatment $4^{\text {th }}$ in the experiment was the best, while the transaction number 7 of the experiment was the lowest by about 1.14 , that means that the revenues cover the costs once and fourteen percent, It is illustrated from the previous presentation that each of the transactions number 3, 4, 5, 6 and 7 of the experiment treated with bio-pesticide is economically feasible compared to the other experiments of transactions $(1,2,8$, $9,10)$ and treatment number 4 is the best treatment in terms of technical and economic as it achieved the highest productivity and the highest return on the invested pound.

\section{Economic Evaluation Loss:}

It is Illustrated from the data in table (6) to measure the economic impact of the use of biopesticides on the losses of different treatments - and since the treatment number 4 was the best economically, it was considered the standard treatment for the economic comparison of the loss - that the productive losses reached below the treatment No. 5 at $35.2 \mathrm{~kg} /$ block estimated at $63.6 \mathrm{~L}$. E., while the highest production losses for treatment 10 (control) in were estimated at $474.9 \mathrm{~kg} /$ block equivalent to about $854.8 \mathrm{~L}$. E. As for the losses incurred in the inputs of production, it turns out that the losses in the land amounted to about $3.37 \mathrm{~m} 2$ in the treatment number 5 in the experiment equal to the value of about 3.8 L. E. The highest land lose was in treatment number 10 (control) of about 45 $\mathrm{m} 2$ estimated value of about 52 L.E., Regarding the loss of seedlings, the data indicated that it reached a minimum of about $2.5 \mathrm{~L}$. E for treatment No. 5 in the experiment, while its highest limit was about 34.7 L. E for treatment No. 10 (control), which was not treated with bio-pesticides. Also, the cost of loss in organic fertilizer amounted to the lowest for treatment No. 5 in the experiment by about $5.5 \mathrm{~L}$. E, while the highest losses came in treatment number 10 (control) estimated at about $75.8 \mathrm{~L}$. E. Chemical fertilizer losses reached the lowest value for treatment no. 5 in the experiment, estimated at L,E 10.06, while the maximum value for treatment no. 10 was (control). With regard to water losses, data show that the lowest value in treatment number 5 was estimated at $14.7 \mathrm{~L}$. E, while the highest 
Table 5: Some Economic Evaluation Indicators Associated with Tomato Elisa cultivar in Giza Governorate (Value in LE - Quantity in kg - Surface Area).

\begin{tabular}{|c|c|c|c|c|c|c|c|c|c|c|c|}
\hline Treatment spraying*/ Items & 1 & 2 & 3 & 4 & 5 & 6 & 7 & 8 & 9 & 10 & Average \\
\hline Cost of bio-pesticides EGP & 57.00 & 114.00 & 171.00 & 228.00 & 285.00 & 342.00 & 399.00 & 456.00 & 513.00 & 0.00 & 256.50 \\
\hline Total cost EGP & 319.00 & 376.00 & 433.00 & 490.00 & 547.00 & 604.00 & 661.00 & 718.00 & 775.00 & 262.00 & 518.50 \\
\hline Productivity kg & 127.40 & 156.70 & 364.00 & 548.00 & 512.90 & 512.70 & 420.20 & 236.30 & 208.70 & 73.10 & 316.00 \\
\hline Price of kg EGP & 1.80 & 1.80 & 1.80 & 1.80 .00 & 1.80 & 1.80 & 1.80 & 1.80 & 1.80 & 1.80 & 1.80 \\
\hline Total Revenue EGP & 229.30 & 282.00 & 655.20 & 986.40 & 923.10 & 922.80 & 756.40 & 425.30 & 375.70 & 131.60 & 568.80 \\
\hline Net revenue EGP & -89.70 & -94.00 & 222.20 & 496.40 & 376.10 & 318.80 & 95.40 & -292.70 & -399.30 & -130.40 & 50.30 \\
\hline Return on Pound & -0.28 & -0.25 & 0.51 & 1.01 & 0.69 & 0.53 & 0.14 & -0.41 & -0.52 & -0.50 & 0.10 \\
\hline CBR & 0.72 & 0.75 & 1.51 & 2.01 & 1.69 & 1.53 & 1.14 & 0.59 & 0.48 & 0.50 & 1.10 \\
\hline Area $\mathbf{m}^{2}$ for the treatment & 52.50 & 52.50 & 52.50 & 52.50 & 52.50 & 52.50 & 52.50 & 52.50 & 52.50 & 52.50 & 52.50 \\
\hline
\end{tabular}

Source: Collected from the field experiment data*Spraying: the number of times spraying the bio-pesticide, which is arranged from 1: 10 and the treatment number 10 control did not use any spraying

Table 6: Economic evaluation of Elisa tomato crop loss in Giza Governorate (value in LE - quantity in $\mathrm{Kg}$ - surface area)

\begin{tabular}{|c|c|c|c|c|c|c|c|c|c|c|c|}
\hline Treatment spraying*/ Items & 1 & 2 & 3 & 4 & 5 & 6 & 7 & 8 & 9 & 10 & Average \\
\hline Productivity losses kg & 420.6 & 391.4 & 184.0 & 0.0 & 35.2 & 35.3 & 127.8 & 311.7 & 339.3 & 474.9 & 232.0 \\
\hline Value of productive losses EGP & 757.1 & 704.4 & 331.2 & 0.0 & 63.3 & 63.6 & 230.0 & 561.1 & 610.7 & 854.8 & 417.6 \\
\hline Wastage in the land in meters & 40.0 & 37.0 & 18.0 & 0.0 & 3.37 & 3.38 & 12 & 30.0 & 33.0 & 45.0 & 22.0 \\
\hline The value of wastage in the land EGP & 46.1 & 42.8 & 20.1 & 0.0 & 3.8 & 3.9 & 14.0 & 34.1 & 37.1 & 52.0 & 25.4 \\
\hline Value of losses in seedlings EGP & 30.7 & 28.6 & 13.4 & 0.0 & 2.6 & 2.6 & 9.3 & 22.8 & 24.8 & 34.7 & 16.9 \\
\hline Value of organic fertilizer losses EGP & 67.1 & 62.5 & 29.4 & 0.0 & 5.6 & 5.6 & 20.4 & 49.7 & 54.1 & 75.8 & 37.0 \\
\hline Value of chemical fertilizer losses EGP & 120.8 & 112.4 & 52.9 & 0.0 & 10.1 & 10.1 & 36.7 & 89.5 & 97.5 & 136.4 & 66.6 \\
\hline Value of water losses EGP & 33.6 & 31.2 & 14.7 & 0.0 & 2.8 & 2.8 & 10.2 & 24.9 & 27.1 & 37.9 & 18.5 \\
\hline Total value of production input losses EGP & 298.3 & 277.5 & 130.5 & 0.0 & 24.9 & 25.0 & 90.6 & 221.1 & 240.6 & 336.7 & 164.5 \\
\hline
\end{tabular}
spraying. 
value of water loss came in treatment number 10 (control) of about $37.9 \mathrm{~L}$. E. The total value of production input losses was the lowest value of transaction number 5 in the experiment, estimated at L.E 28.6, while the highest value of the total input losses was about LE 299.2 for treatment number 10 (control).

\section{Economic Evaluation of yield weight:}

The data in Table (7) shows that the average yield of tomatoes per Fadden reached about 24 tons per Fadden, ranging from a minimum of about 5.6 tons per Fadden for treatment No. 10 (control) and a maximum of about 41.7 tons per Fadden for treatment No. 4 experiment, total cost per Fadden averaged about 23.01 pounds per Fadden, where the lowest cost for transaction number 10 (control) was about 20.9 thousand pounds per Fadden, while the highest cost was about 25.1 thousand pounds per Fadden for transaction number 9, As for the total revenue per Fadden in the experiment, it is clear from the data that it averaged about 43.3 thousand pounds. Where it achieved the lowest revenue per Fadden for transaction No. 10 (control) while the best revenue per Fadden came in transaction No. 4 of about 75.15 thousand pounds per Fadden. The net return on the average value of the experiment is about 20.3 thousand pounds per Fadden, where the transaction number 10 achieved the maximum loss estimated by about 10.9 thousand pounds per Fadden, while the transaction number 4 in the experiment achieved the highest net return estimated at about 52.4 thousand pounds per Fadden. This difference in productivity, costs, revenues and net return is due to the positive impact of the use of the bio-pesticide on productivity and economic of scale, especially in each of the treatment number 4 and 9 of the experiment and thus the positive impact on revenue and net return where the best transactions in terms of those indicators compared to the rest of the transactions in the experiment.

As for the economic valuation indicators, the data indicates that the return on the invested L.E has achieved a loss of transactions 1, 2 and 10 on the Fadden experience, while the highest value was about 2.3 for the transaction number 4 at the level of the Fadden, The benefit -cost ratio (CBR) of that crop shows that transaction 4 was the best, with CBR at 3.3, meaning that the cost covers the costs three times and a third. It is illustrated from the previous presentation that each of the treatment No. 3, $4,5,6,7,8,9$ by the experiment with bio-pesticide treatment is economically feasible compared to the other experiments of treatment $(1,210)$ and treatment number 4 by the experiment is technically the best treatment. In addition to the improved yield and the highest return on the invested pound at the level, this in addition to the improved return on the invested pound for treatment No. 8, 9 per Fadden compared to the experience area of $52.5 \mathrm{~m}^{2}$, which is due to the achievement of capacity savings at the level of Fadden.

\section{Economic Evaluation of Losses for big unites Fadden:}

Data in table (8) indicated that measuring the economic impact of the use of bio-pesticides on the loss of various treatments at the level of Fadden and since the treatment number 4 was the best economically; it was considered the standard treatment for economic comparison of the loss. On average, it reached 17.7 tons per Fadden with an average value of about 31.8 thousand L.Es per Fadden. Where the lowest production losses came in the treatment No. 5 about 2.6 tons per Fadden, the estimated value of about 4.7 thousand L.Es per Fadden, While the above production losses of treatment 10 (control) were estimated at 36.2 tons per Fadden equivalent to about 65.1 thousand L.Es, As for the losses incurred in the production inputs, it turns out that the losses in the land amounted to an average of about 10.4 Fadden estimated at about 2.1 thousand L.Es per Fadden. but losses of seedlings, organic fertilizer, fertilizer and irrigation water averaged about 6.2 thousand L.Es per Fadden, ranging from a minimum amount of about 943.7 L.Es per Fadden for transaction No. 5 and a maximum loss of about 12.7 thousand L.Es per Fadden in transaction number 10 (control).

\section{Economic Evaluation on the governorate level:}

Table (9) showed that the average area of tomatoes in Giza Governorate during 2017 amounted to about 8.77 thousand Fadden. If the number 10 is controlled by the experiment, and a maximum of about 366.3 thousand tons if the number 4 is adopted by the experiment, The average value of tomato production in the governorate was about EGP 380.14 million, with a minimum value of EGP 87.9 million for treatment 10 and a maximum of EGP 659.2 million for treatment No. 4. 10 
Table 7: Some economic evaluation indicators associated with tomato crop of Elisa Fadden in research experiment in Giza Governorate

\begin{tabular}{|c|c|c|c|c|c|c|c|c|c|c|c|}
\hline Treatment spraying*/ Items & 1 & 2 & 3 & 4 & 5 & 6 & 7 & 8 & 9 & 10 & Average \\
\hline Cost of bio-pesticides EG & 456 & 912 & 1368 & 1824 & 2280 & 2736 & 3192 & 3648 & 4104 & 0 & 2052 \\
\hline Total cost EGP & 21416 & 21872 & 22328 & 22784 & 23240 & 23696 & 24152 & 24608 & 25064 & 20960 & 23012 \\
\hline Productivity per ton & 9.71 & 11.94 & 27.73 & 41.75 & 39.07 & 39.06 & 32.02 & 18.00 & 15.90 & 5.57 & 24.1 \\
\hline Price (EGP / kg) & 1.80 & 1.80 & 1.80 & 1.80 & 1.80 & 1.80 & 1.80 & 1.80 & 1.80 & 1.80 & 1.80 \\
\hline Total revenue EGP & 17472.0 & 21483.4 & 49920.0 & 75154.3 & 70333.7 & 70311.4 & 57630.9 & 32403.4 & 28626.0 & 10028.6 & 43336.4 \\
\hline Net revenue EGP & 3944 & 389 & 27592 & 52370 & 47094 & 46615 & 33479 & 7795 & 3562 & 10931 & 20324.4 \\
\hline Return on EGP & 0.18 & 0.02 & 1.24 & 2.30 & 2.03 & 1.97 & 1.39 & 0.32 & 0.14 & 0.52 & 0.9 \\
\hline CBR & 0.82 & 0.98 & 2.24 & 3.30 & 3.03 & 2.97 & 2.39 & 1.32 & 1.14 & 0.48 & 1.9 \\
\hline Value added EGP & 7216.0 & 10771.4 & 38752.0 & 63530.3 & 58253.7 & 57775.4 & 44638.9 & 18955.4 & 14722.0 & 228.6 & 31484.4 \\
\hline
\end{tabular}

Source: Collected from the field experiment data*Spraying: the number of times spraying the bio-pesticide, which is arranged from 1: 10 and the treatment number 10 control did not use any spraying.

Table 8: Economic evaluation per Fadden of tomato crop loss Elisa cultivar in Giza Governorate (value in L.Es - quantity in tons)

\begin{tabular}{|c|c|c|c|c|c|c|c|c|c|c|c|}
\hline Treatment *Spraying / Items & 1 & 2 & 3 & 4 & 5 & 6 & 7 & 8 & 9 & 10 & Average \\
\hline Production losses per ton & 32.0 & 29.8 & 14.0 & 0.0 & 2.7 & 2.7 & 9.7 & 23.8 & 25.8 & 36.2 & 17.7 \\
\hline Value of productive losses in thousand EGP & 57.7 & 53.7 & 25.2 & 0.0 & 4.8 & 4.8 & 17.5 & 42.8 & 46.5 & 65.1 & 31.8 \\
\hline Lost in the carat land & 18.9 & 17.5 & 8.2 & 0.0 & 1.6 & 1.6 & 5.7 & 14.0 & 15.2 & 21.3 & 10.4 \\
\hline Value of losses in the land & 3770.1 & 3507.9 & 1649.3 & 0.0 & 315.1 & 316.5 & 1145.3 & 2794.2 & 3041.1 & 4256.6 & 2079.6 \\
\hline The value of losses in seedlings EGP & 2456.1 & 2285.3 & 1074.5 & 0.0 & 205.3 & 206.2 & 746.1 & 1820.3 & 1981.1 & 2773.0 & 1354.8 \\
\hline Value of organic fertilizer losses EGP & 1535.0 & 1428.3 & 671.5 & 0.0 & 128.3 & 128.9 & 466.3 & 1137.7 & 1238.2 & 1733.1 & 846.7 \\
\hline Value of chemical fertilizer losses EGP & 2763.1 & 2570.9 & 1208.8 & 0.0 & 230.9 & 232.0 & 839.4 & 2047.8 & 2228.8 & 3119.6 & 1524.1 \\
\hline Value of water losses EGP & 767.5 & 714.1 & 335.8 & 0.0 & 64.1 & 64.4 & 233.2 & 568.8 & 619.1 & 866.6 & 423.4 \\
\hline The total value of production input losses EGP & 11291.8 & 10506.5 & 4939.8 & 0.0 & 943.7 & 948.0 & 3430.3 & 8368.8 & 9108.3 & 12748.9 & 6228.6 \\
\hline
\end{tabular}

Source: Collected from the field experiment data*Spraying: the number of times spraying the bio-pesticide, which is arranged from 1: 10 and the treatment number 10 control did not use any spraying. 
Table 9: Economic evaluation of the generalization of the results of the research experiment for tomato crop Elisa cultivar at Giza level

\begin{tabular}{|c|c|c|c|c|c|c|c|c|c|c|c|}
\hline Treatment $*$ Spraying / Items & 1 & 2 & 3 & 4 & 5 & 6 & 7 & 8 & 9 & 10 & Average \\
\hline Area for the governorate in Fadden & 8772 & 8772 & 8772 & 8772 & 8772 & 8772 & 8772 & 8772 & 8772 & 8772 & 8772.0 \\
\hline Total production of the governorate in thousand tons & 85.1 & 104.7 & 243.3 & 366.3 & 342.8 & 342.7 & 280.9 & 157.9 & 139.5 & 48.9 & 211.2 \\
\hline The total cost of the governorate in million L.Es & 188.0 & 192.0 & 196.0 & 200.0 & 204.0 & 208.0 & 212.0 & 216.0 & 220.0 & 184.0 & 201.9 \\
\hline Production value of the governorate in million L.Es & 153.0 & 188.0 & 438.0 & 659.0 & 617.0 & 617.0 & 506.0 & 284.0 & 251.0 & 88.0 & 380.1 \\
\hline Net profit / loss of the governorate in million L.Es & -35.0 & -3.0 & 242.0 & 459.0 & 413.0 & 409.0 & 294.0 & 68.0 & 31.0 & -96.0 & 178.3 \\
\hline The added value of the governorate in million L.Es & 63.3 & 94.5 & 339.9 & 557.3 & 511.0 & 506.8 & 391.6 & 166.3 & 129.1 & 2.0 & 276.2 \\
\hline Production losses in thousand tons & 281.1 & 261.6 & 123.0 & 0.0 & 23.5 & 23.6 & 85.4 & 208.3 & 226.7 & 317.4 & 155.1 \\
\hline Value of productive losses in million L.Es & 506.0 & 470.8 & 221.4 & 0.0 & 42.3 & 42.5 & 153.7 & 375.0 & 408.1 & 571.3 & 279.1 \\
\hline Loss of land in the thousand Fadden & 29.0 & 21.9 & 4.4 & 0.0 & 0.6 & 0.6 & 2.7 & 11.6 & 14.3 & 57.0 & 14.2 \\
\hline Value of land losses in million L.Es & 139.0 & 105.2 & 21.3 & 0.0 & 2.9 & 2.9 & 12.8 & 55.6 & 68.4 & 273.4 & 68.1 \\
\hline Value of losses in seedlings in million L.Es & 21.5 & 20.0 & 9.4 & 0.0 & 1.8 & 1.8 & 6.5 & 16.0 & 17.4 & 24.3 & 11.9 \\
\hline Value of losses in organic fertilizer in million L.Es & 13.5 & 12.5 & 5.9 & 0.0 & 1.1 & 1.1 & 4.1 & 10.0 & 10.9 & 15.2 & 7.4 \\
\hline Value of losses in chemical fertilizers in million L.Es & 24.2 & 22.6 & 10.6 & 0.0 & 2.0 & 2.0 & 7.4 & 18.0 & 19.6 & 27.4 & 13.4 \\
\hline Value of water losses in million L.Es & 6.7 & 6.3 & 2.9 & 0.0 & 0.6 & 0.6 & 2.0 & 5.0 & 5.4 & 7.6 & 3.7 \\
\hline Total value of output input losses & 205.0 & 166.6 & 50.1 & 0.0 & 8.4 & 8.4 & 32.8 & 104.5 & 121.7 & 347.9 & 104.5 \\
\hline
\end{tabular}


The governorate will achieve a loss of 34.6, 3.4 and 95.9 L.Es million each, respectively, In the case of relying on treatment.

\section{Discussion}

Obtained results are in line with Tadele and Emana 2018, this study shows that the determination of economic injury level and economic threshold level tool for timely control of $T$. absoluta under glasshouse conditions in Ethiopia is better than the most common current practice of insecticide applications. For Tomato growers under favorable climatic conditions, T. absoluta infestations 2.25 larvae/plant do not affect tomato yield under glasshouse conditions. Results of the present study revealed that the control measures should be initiated when the $T$. absoluta larval population reaches 2.25 larvae per plant in glasshouse in order to prevent the population from reaching economic injury levels. and Mona et al. 2018, found data indicated that (General Equilibrium Position (G.E.P.)) between 55 to 61 larvae/20 leaves, Economic Threshold Level (E.T.L)] between 57 to 72 larvae / 20 leaves, [Economic Injury Level (E.I.L)], 78 to 103 larvae / 20 leaves at this level of infestation control measures must be applied to be used as a tool for controlling Tuta absoluta under Field conditions. Data in case of root knot nematodes agree with Korayem et al., 2012 found that the Damage threshold nematode density was observed at which loss in yield begin to decrease was $830 \mathrm{~J} 2 / 200 \mathrm{~g}$ soil and $1000 J 2 / 200 \mathrm{~g}$ soil for Diamont and Désirée, respectively .

Moreover, Korayem et al., (2015) found that the first season, the relation between nematode initial population density and bean yield was significantly negative $(\mathrm{r}=-0.6)$. A significant reduction in bean yield $(\mathrm{P}=0.05)$ was obtained when nematode density was more than $100 \mathrm{~J} 2 / 200 \mathrm{~g}$ soil. While, damage threshold level (DT); nematode density at which yield begin to decrease; was estimated by $3 \mathrm{~J} 2 / 200 \mathrm{~g}$ soil. For the second season, no significant relation $(\mathrm{P}=0.05)$ between nematode population density and bean yield was found $(\mathrm{r}=0.33)$. DT was estimated as $22 \mathrm{~J} 2 / 200 \mathrm{~g}$ soil .

Economic analysis results of the management of tomato crop of the present study agree with Tadele and Emana 2018 the mean values of marketable yield gained to the cost of insecticide application at 0,1 and 4 larvae per plant were $34,913,31,006$ and 16,574.5 kg/ha from 2015 to 2016, respectively. The lowest yield was observed at control/unsprayed treatment $(7,751.5 \mathrm{~kg} / \mathrm{ha})$.

\section{Conclusion}

The determination of economic infestation threshold level and economic injury level of $T$. absoluta and M. incognita to be used as a tool for controlling under Field conditions was done. Data indicated that T. absoluta Economic Threshold Level (E.T.L)] between 40 to 49 larvae / 20 leaves, [Economic Injury Level ( E.I.L)], 49 to 84 larvae / 20 leaves at this level of infestation control measures must be applied. M. incognita soil naturally infected with nematodes, data indicated that (E.T.L) between 95 to $114 \mathrm{~J} 2 / 200 \mathrm{~g}$ soil, ( E.I.L), 114 to $170 \mathrm{~J} 2 / 200 \mathrm{~g}$ soil at this level of infestation control measures must be applied. It is clear that based on the results of the economic evaluation should be recommended to rely on the treatment fourth by the experiment, which provides for spraying the bio-pesticide to resist the pest four times according to the technical recommendation, which has a positive impact on the net return and province.

\section{References}

Alston, D. 2007. Insect Pests in Greenhouse and Nursery Crops. Utah State University Extension Utah Green Conference January 22, 2007, 55 PP.

Arora, R., G.S. Battu and N. Ramakrishnan, 2000. Microbial pesticides current status and future outlook. In: Bio-pesticides and Environment. (Eds). G. S. Dhaliwal and B. Singh. Commonwealth Publishers, New Delhi, pp. 344- 395.

Barker, K.R., and C.J. Nusbaum, 1971. Diagnostic and advisory programs, pp. 281-301. In plant parasitic nematodes vol. 1, ed. B. M. Zuckerman, W. F. Mai and R. A. Rhode, Academic Press, New York, p. 345.

Barker KR,and T.H.A. Olthuf, 1976. Relationship between nematode population densities and crop responses. Ann. Rev. Phytopathol. 14: 327-353. 
Desneux, N., E Wajnberg, K.A.G. Wyckhuys, G. Burgio, S. Arpaia, C.A. Narváez-Vasquez, J. González-Cabrera, D Catalán Ruescas, E Tabone, J Frandon, J Pizzol, C Poncet, T Cabello,and A. Urbaneja, 2010. Biological invasion of European tomato crops by Tuta absoluta: ecology, geographic expansion and prospects for biological control. Journal of Pest Science 83: 197-215.

El-Nagdi, W.M.A., 2001. Studies on banana nematodes in Egypt. PhD thesis, Fac Agric, Cairo Univ, Egypt, 179 pp

El-Nagdi, M. A. W. and M. M. A. Youssef .2004. Soaking faba bean seed in some bio-agents as prophylactic treatment for controlling Meloidogyne incognita root-knot nematode infection J Pest Sci, 77: 75-78. DOI 10.1007/s10340-003-0029-y

El-Nagdi, M. A. W., H. Abd-El-Khair, M. G. Soliman, H. H. Ameen and Gh. M. El-Sayed, 2019. Application of protoplast fusants of Bacillus licheniformis and Pseudomonas aeruginosa on Meloidogyne incognita in tomato and eggplant. Middle East Journal of Applied Sciences, 9 (2): 622-629.

Eloh, K., N.Sasanelli, A. Maxia, and P.Caboni, 2016. Untargeted metabolomics of tomato plants after root-knot nematode infestation. J. Agric. Food Chem. 2016, 64، 5963-5968.

EPPO. 2008. Additional information provided by Spain on EPPOA1 pest. EPPO reporting service (ESTa/2008-01).

EPPO. 2009. First report of Tuta absoluta in France. EPPO reporting service 2009/003.

FERA. 2009.The first outbreak of the South American tomato moth Tuta absoluta in the U.K. Available at: http://www.fera.defra.gov.uk.

Gilardo'n, E., M. Pocovi, C. Hernade'z, and A. Olsen. 2001. Papel dos tricomas glandulares da folha do tomateiro na oviposica o de Tuta absoluta. Pesq Agrop Brasileira 36:585-8.

Khalil, S. M., 2013. Abamectin and Azadirachtin as Eco-friendly Promising Biorational Tools in Integrated Nematodes Management Programs. J Plant Pathol Microb 4: 174 doi:10.4172/21577471.1000174

Khan, M. R., R. K. Jain, R. V. Singh, and A. Pramanik, 2010. Economically Important Plant Parasitic Nematodes Distribution Atlas. Directorate of Information and Publications of Agricuture, New Delhi. pp: 10.

Korayem, A.M., M.A.Y. Mahmoud,and M.M.M. Moawad, 2008. Effect of chitin and abamectin on Meloidogine incognita infesting rapeseed. J. Plant Protection Res. 48 (3): 365-370.

Korayem, A.M., M.M.M. Mohamed and S.D. Abou - Hussein, 2012. Damage Threshold of RootKnot Nematode Meloidogyne arenaria to Potatoes Grown in Naturally and Artificially Infected Fields and its Effect on Some Tubers Properties. Journal of Applied Sciences Research, 8(3): $1445-1452$.

Korayem, A.M., M.M.M. Mohamed and S.M. EL-Ashry, 2015. amage threshold of Meloidogyne arenaria to common bean influenced by dates of planting. Pakistan Journal of Nematology, 33(1): 87-92

Korayem, A.M., E.M.A. Noweer, and M.M.M. Mohamed, 2008. Threshold population of Meloidogyne species causing damage to some vegetable crops under certain conditions in Egypt. Egyptian Journal of Agronematology 6, 217-227.

Maha S. El-Ghanam, Hammam M. A. Nasser and Mona N. WahbaEffect of Intercropping of two Aromatic Plants and two Treatments against Infestation of Liriomyza Trifolli (Burgess) on two Green Pea Plants and Economic Evaluation of Yield, Middle East Journal of Agriculture Research, Volume : 05 | Issue : 04 | Oct.-Dec. | 2016 Pages: 455-461.

Ministry of Agriculture and land reclamation, Economic Affairs Sector, "Agricultural Economics Bulletin", various issues

Mona. I. Ammar; Soliman, M. H. A. and EL- Roby, AFAF.M.S 2018. Loss assessment and the estimation of Economic Infestation levels of Tuta absoluta (Meyrick) in tomato crops ELSharkia Governorate. Egyptian Journal of Agricultural Research. Vol. 96 Issue 4, p1369-1377.

Nasser, M. A. H., 2006. Economics of Production and Marketing Tomatoes in Egypt, Unpublished M. Sc. Thesis, Ain Shams University, Faculty of Agriculture, Agricultural Economics Department,

Omura, S. K. S. 2007. Discovery, chemistry, and chemical biology of microbial products. Pure Appl Chem 79: 581-591. 
Osman, H.A., M.M.A. Youssef, A.Y. El-Gindi, H.H. Ameen, N.A. Abd-Elbary ,and A.M.S. Lashein, 2012. Effect of salicylic acid and Pseudomonas fluorescens against Meloidogyne incognita in eggplant using split-root technique. Pakistan Journal of Nematology 30 (2): 101-113.

Pedigo, L.P., S.H. Hutchins and L.G. Higley, 1986. Economic injury levels in theory and practice. Ann. Rev. Entom.; 31: 341-368.

Pitterna, T., J. Cassayre, O.F. Hüter, P.M. Jung, P. Maienfisch, et al. 2009. New ventures in the chemistry of avermectins. Bioorg Med Chem 17: 4085-4095.

Sabbour, M.M. 2014. Biocontrol of the Tomato Pinworm Tuta absoluta (Meyrick) (Lepidoptera: Gelechiidae) in Egypt. Middle East Journal of Agriculture Research, 3(3): 499-503,

SAS Institute. 1999. SAS/STAT. guide for personal computers. SAS Institute.

Sikora, R.A. and E. Fernandez. 2005. Nematodes parasites of vegetables. In: Plant Parasitic Nematodes in Tropical and Subtropical Agriculture, (Eds) Luc, M., R.A. Sikora and J. Bridge Second Ed. CAB International, Wallingford, Oxford OX10 8DE, UK, pp. 319-392.

Tadele, S., and E. Getu, 2018. Determination of the economic threshold level of tomato leaf miner, Tuta absoluta Meyrick (Lepidoptera: Gelechiidae) on tomato plant under glasshouse conditions. Journal of Horticulture and Forestry. Vol. 10(2), pp. 9-16.

Tropea, G. G., G. Siscaro, A. Biondi, and. L. Zappala'. 2012. Tuta absoluta, a South American pest of tomato now in the EPPO region: biology, distribution and damage. EPPO Bull 42:205-10.

Varkeya, S., K.N. Anitha, R. Narayanab, and S. Aswinia, 2018. A consortium of rhizobacteria and fungal endophyte suppress the root-knot nematode parasite in tomato. Rhizosphere (5) 38-42 21.Miller TW, Chaiet L, Cole DJ, Cole LJ, Flor JE, et al. (1979) Avermectins, new family of potent anthelmintic agents: isolation and chromatographic properties. Antimicrob Agents Chemother 15: 368-371.

WPTC, 2019. Report of World Processing Tomato Council, 30 August 2019, 1 pp. 